Article

\title{
Intercalation and Exfoliation of Kaolinite with Sodium Dodecyl Sulfate
}

\author{
Xiaochao Zuo ${ }^{1,2}$, Ding Wang ${ }^{3}$, Shilong Zhang ${ }^{3}$, Qinfu Liu ${ }^{3, *}$ and Huaming Yang ${ }^{1,2, *}$ (D) \\ 1 Centre for Mineral Materials, School of Minerals Processing and Bioengineering, \\ Central South University, Changsha 410083, China; xiaochaozuo@csu.edu.cn \\ 2 Hunan Key Lab of Mineral Materials and Application, Central South University, Changsha 410083, China \\ 3 School of Geoscience and Surveying Engineering, China University of Mining \& Technology, \\ Beijing 100083, China; wangding0313@163.com (D.W.); cailiaoa007@163.com (S.Z.) \\ * $\quad$ Correspondence: lqf@cumtb.edu.cn (Q.L.); hmyang@csu.edu.cn (H.Y.); Tel.: +86-731-88830549 (H.Y.)
}

Received: 24 January 2018; Accepted: 7 March 2018; Published: 9 March 2018

\begin{abstract}
Kaolinite (Kaol) was intercalated with dimethyl sulfoxide (DMSO) and subsequently methanol (MeOH) to prepare intercalation compounds Kaol-DMSO and Kaol-MeOH. Kaol-MeOH was used as an intermediate to synthesize Kaol-sodium dodecyl sulfate (SDS) intercalation compound (Kaol-SDS) via displacement reaction. The ultrasonic exfoliation of Kaol-SDS produced a resultant Kaol-SDS-U. The samples were characterized by X-ray diffraction (XRD), Fourier transformation infrared spectroscopy (FTIR), thermal analysis, scanning electronic microscopy (SEM), transmission electron microscopy (TEM) and particle size analysis. The results revealed that the intercalation of sodium dodecyl sulfate into kaolinite layers caused an obvious increase of the basal spacing from $0.72-4.21 \mathrm{~nm}$. The dehydroxylation temperature of Kaol-SDS was obviously lower than that of original kaolinite. During the intercalation process of sodium dodecyl sulfate, a few kaolinite layers were exfoliated and curled up from the edges of the kaolinite sheets. After sonication treatment, the kaolinite layers were further transformed into nanoscrolls, and the exfoliated resultant Kaol-SDS-U possessed a smaller particle size close to nanoscale.
\end{abstract}

Keywords: kaolinite; intercalation; exfoliation; sodium dodecyl sulfate

\section{Introduction}

Recently, rubber/layered silicate nanocomposites have attracted extensive interest both in industry and academia due to the unique characteristics of nano-sized layered silicates, including their large surface area, high surface reactivity and relatively low cost [1-4]. The layered silicates used in rubbers can increase mechanical properties, improve thermal resistance and reduce gas permeability [2,5,6]. It is well known that layered silicates with large aspect ratios added in rubber are more beneficial to increase the tortuosity of the diffusive path for the gas molecule, providing excellent barrier properties $[2,7,8]$. However, the raw layered silicates have a disc-like structure with a low aspect ratio. Therefore, many efforts have been made to increase the aspect ratio of layer silicates [9-13].

Kaolinite (Kaol), $\mathrm{Al}_{2} \mathrm{Si}_{2} \mathrm{O}_{5}(\mathrm{OH})_{4}$, is a typical 1:1 layered dioctahedral aluminum silicate, which has been widely used as a filler in rubber [6,14-17]. The layers of kaolinite are composed of $\mathrm{SiO}_{4}$ tetrahedral sheets linked to $\mathrm{AlO}_{2}(\mathrm{OH})_{4}$ octahedral sheets. The adjacent layers are tightly held together by hydrogen bonds between hydroxyl groups on the octahedral (aluminum) sheets and the tetrahedral (silicon) sheets. In order to increase the accessible aspect ratio of kaolinite, many methods have been used to exfoliate the stack layers of kaolinite, such as intercalation, mechanical exfoliation and assisted sonication [18-21]. Among these exfoliation methods, intercalation has received considerable attention because the intercalated molecules could not only weaken the hydrogen bonding, but also provide space for kaolinite to be exfoliated $[19,22,23]$. Nevertheless, only a limited number of polar guest 
species can be intercalated directly into kaolinite, such as urea [24,25], potassium acetate [26-29] and dimethyl sulfoxide [30,31]. Moreover, kaolinite would not be exfoliated even though these species were intercalated into kaolinite layers due to the strong inner hydrogen bonds between the layers.

Actually, natural minerals have been widely used for the preparation of advanced materials [32-46]. Much work has been done to demonstrate that various intercalated guest species can be extended by the "displacement method". Especially the methoxy-modified kaolinite shows more versatility for further intercalation reactions. For example, Komori et al. reported that kaolinite-alkylamines intercalation compounds were prepared by using the methanol-treated kaolinite intercalation as an intermediate $[47,48]$. The results showed that the basal spacing increased up to $5.75 \mathrm{~nm}$ when octadecylamine was used. Matusik et al. prepared kaolinite intercalation compounds with benzylalkylammonium chlorides [49,50]. They have reported that a methoxy-modified kaolinite was used as a precursor, which had $\mathrm{OCH}_{3}$ methoxyl groups attached to the octahedral sheet. Additionally, Gardolinski and Lagaly [51,52] reported that $n$-hexylamine, $n$-octadecylamine and $n$-docosanamine were intercalated into the layers of kaolinite by the same method reported by Komori and co-workers $[47,48]$. When $n$-docosanamine was used, the largest basal spacing of $6.42 \mathrm{~nm}$ was obtained, and the platy layers transformed into nanoscrolls after the deintercalation performed with toluene. Kuroda et al. also reported that some quaternary ammonium salts intercalated into the interlayers of kaolinite using methoxy-modified kaolinite as an intermediate, and most of the exfoliated kaolinite layers also transformed into nanoscrolls [19]. Liu et al. demonstrated kaolinite layers got curled up into one-dimensional nanoscrolls automatically when they are exfoliated in methanol after intercalation with alkyltrimethylammonium salts [53]. This depicted the morphological change of kaolinite layers during intercalation and exfoliation.

The guest species mentioned above were defined as cationic intercalators, because they could be ionized to produce cations. In the case of intercalation, after kaolinite stacking layers reacted with cationic long chain intercalators, the layer-to-layer distance expanded, and the binding forces of adjacent layers decreased significantly. The kaolinite layers were lastly exfoliated and curled up into nanoscrolls. Therefore, it is not a good way to obtain kaolinite with a high aspect ratio. Based on the literature described above, little attention has been paid to the intercalation of kaolinite with anionic guest species. Sidheswaran et al. [54] firstly examined the preparation of intercalation compounds of kaolinite by a one-step displacement method with the salts of long-chain fatty acids. The results indicated that the expanded basal spacing of kaolinite was independent of the chain length of guest species, because the basal spacing of kaolinite expanded from $0.7-1.1 \mathrm{~nm}$. Wang et al. [55] recently reported that the interlayer spacing of kaolinite was enlarged to $4.55 \sim 4.79 \mathrm{~nm}$ intercalated by sodium stearate using the methoxy-modified kaolinite as the precursor.

In this work, as an important anionic surfactant, SDS was intercalated into kaolinite layers using Kaol-MeOH as the initial material first. Afterwards, the Kaol-SDS was treated by the sonication method. It was found that the morphology of most exfoliated kaolinite layers remained intact. The exfoliation method may provide the possibility of preparing thin kaolinite flakes with large aspect ratios.

\section{Materials and Methods}

\subsection{Materials}

The kaolinite (Kaol) used in the present study with a Hinckley index of 1.31, obtained from Zhangjiakou, China, was used as received. The chemical composition of purified kaolinite is listed in Table 1. Dimethyl sulfoxide (DMSO) and methanol (MeOH) were obtained from Xilong Chemical Co., Ltd., Beijing, China. Sodium dodecyl sulfate (SDS) was provided by Sinopharm Chemical Regent Co., Ltd., Beijing, China. Hydrochloric acid $(\mathrm{HCl})$ was purchased from Beijing Chemical Plant (Beijing, China). All reagents were of analytical-grade purity $(>99.0 \%)$ and used as received. 
Table 1. Chemical composition of kaolinite (Kaol) obtained from Zhangjiakou.

\begin{tabular}{ccccccccccc}
\hline Composition & $\mathrm{SiO}_{2}$ & $\mathrm{Al}_{2} \mathrm{O}_{3}$ & $\mathrm{Fe}_{2} \mathrm{O}_{3}$ & $\mathrm{TiO}_{2}$ & $\mathbf{M g O}$ & $\mathrm{CaO}$ & $\mathrm{Na}_{2} \mathrm{O}$ & $\mathbf{K}_{2} \mathrm{O}_{2}$ & $\mathbf{P}_{2} \mathrm{O}_{5}$ & LOI \\
\hline Content (mass \%) & 44.64 & 38.05 & 0.22 & 1.13 & 0.06 & 0.11 & 0.27 & $<0.10$ & 0.13 & 15.06 \\
\hline \multicolumn{10}{c}{ LOI: loss on ignition. }
\end{tabular}

\subsection{Preparation}

To prepare the methoxy-modified Kaol (Kaol-MeOH), the DMSO intercalated Kaol (denoted as Kaol-DMSO) was prepared according to the previous reports [30,31]. Afterwards, preintercalates were mixed with methanol and stirred for 10 days at room temperature. The solution was replaced by fresh methanol every day. Then, the precipitates were centrifuged and closed in a sealed vessel to prevent methanol evaporation. To prepare the SDS intercalated Kaol, $1 \mathrm{~g}$ of wet Kaol-MeOH was dispersed in $20 \mathrm{~mL}$ of $1.0 \mathrm{~mol} / \mathrm{L}$ sodium dodecyl sulfate (SDS) aqueous solutions. The $\mathrm{pH}$ value of the mixture was adjusted to 2 with $1.0 \mathrm{M} \mathrm{HCl}$ solution and stirred at $60{ }^{\circ} \mathrm{C}$ for $72 \mathrm{~h}$. Then, the solid in the mixture was collected by centrifugation and washed thoroughly with distilled water. The successfully prepared kaolinite-sodium dodecyl sulfate intercalation compound was denoted Kaol-SDS. At last, $1 \mathrm{~g}$ Kaol-SDS was mixed with $200 \mathrm{~mL}$ of $0.1 \mathrm{~mol} / \mathrm{L}$ SDS solutions and stirred vigorously for $0.5 \mathrm{~h}$. Then, the resulting mixture was tip sonicated for $2 \mathrm{~h}$ using a Biaosafer ultrasonic cell disrupter at $800 \mathrm{~W}$ under ambient conditions. At last, the ultrasonic product was collected for characterization and designated as Kaol-SDS-U.

\subsection{Characterization}

Powder XRD patterns were obtained by a Rigaku D/max 2500PC X-ray diffractometer (RIGAKU Company, Akishima, Japan) with $\mathrm{CuK} \alpha(\lambda=0.154178 \mathrm{~nm})$ radiation at the scanning rate of $1^{\circ} / \mathrm{min}$ in the $2 \theta$ range of $1-15^{\circ}$, operating at $40 \mathrm{kV}$ and $100 \mathrm{~mA}$. Typically, the samples were firstly dispersed in absolute ethyl alcohol. Then, about $1 \mathrm{~mL}$ of the mixture was dropped on a glass and allowed to air dry. The prepared glass was used for the test. The infrared spectra were collected using a Nicolet Nexus 870 FTIR spectrometer (Thermo Company, Waltham, MA, USA) with a smart endurance single-bounce diamond ATR cell. We transformed the corresponding data into transmission data by using the ONMIC software between 600 and $4000 \mathrm{~cm}^{-1}$, with a resolution of $4 \mathrm{~cm}^{-1}$ and 32 scans. Thermal analysis was recorded with a Mettler Toledo TGA/DSC1/1600HT instrument (Mettler-Toledo Company, Zurich, Switzerland), operated at a heating rate of $10{ }^{\circ} \mathrm{C} / \mathrm{min}$ from room temperature to $1100{ }^{\circ} \mathrm{C}$ under a nitrogen gas atmosphere. Samples for TEM were prepared from dilute suspensions and investigated using a FEI-Tecnai G2 F30 S-TWIN TEM (FEI Company, Eindhoven, The Netherlands) operating at $300 \mathrm{kV}$. The powder samples were dispersed in ethanol by ultrasound for $20 \mathrm{~min}$ and then deposited on holey carbon-coated copper grids. Samples for SEM were prepared by gold-coating powders and analyzed with a Hitachi S-4800 SEM (accelerating voltage of $3 \mathrm{kV}$, Hitachi High-Technologies Company, Tokyo, Japan). The particle size distribution of the samples was measured with the Malvern Mastersizer 2000. The measurements (Malvern Instruments Ltd, Malvern, UK) were conducted in liquid dispersion, i.e., in distilled water with a refractive index for light equal to 1.55. Cycle injection mode was selected, and test times were 1 2 min.

\section{Results and Discussion}

\subsection{XRD Analysis}

Figure 1 shows the XRD patterns of Kaol, Kaol-DMSO, Kaol-MeOH and Kaol-SDS. In the case of Kaol, the (001) reflection can be observed at $12.24(2 \theta)$ with basal spacing of $0.72 \mathrm{~nm}$. After being intercalated with DMSO, a new reflection appeared at $1.14 \mathrm{~nm}$, corresponding to a typical interlayer distance of Kaol-DMSO as described before [30,31]. When the Kaol-DMSO was washed with fresh $\mathrm{MeOH}, \mathrm{MeOH}$ gradually grafted on to the inner-surface hydroxyls of Kaol by an Al-O-C bond [56]. 
The basal spacing of $0.86 \mathrm{~nm}$ of Kaol-MeOH was observed after drying (Figure 1). Upon intercalation of SDS, the basal spacing of Kaol-MeOH increased to $4.21 \mathrm{~nm}$, which was an increase of $3.49 \mathrm{~nm}$ compared to Kaol, indicating the successful intercalation of SDS into Kaol. Additionally, the reflections at $2.07 \mathrm{~nm}$ and $1.36 \mathrm{~nm}$ are assigned to the second and third order diffractions of Kaol-SDS, respectively.

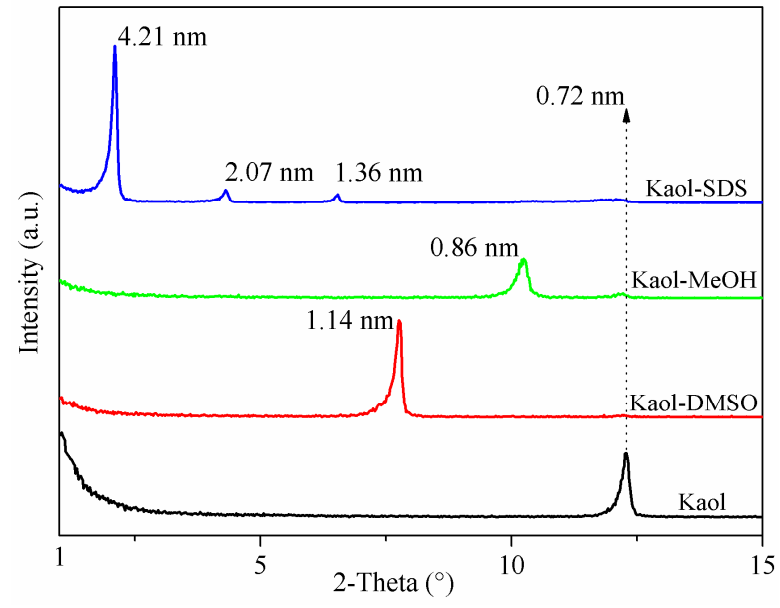

Figure 1. XRD patterns of Kaol and the intercalated Kaol products.

\subsection{FTIR Analysis}

FTIR spectra of Kaol, Kaol-DMSO, Kaol-MeOH and Kaol-SDS with no further treatment are shown in Figure 2. The FTIR spectrum of Kaol was characterized by hydroxyl stretching peaks at 3690 and $3620 \mathrm{~cm}^{-1}$. A shoulder of the large $3690 \mathrm{~cm}^{-1}$ at around $3665 \mathrm{~cm}^{-1}$ could be clearly observed in the raw Kaol. The band at $3620 \mathrm{~cm}^{-1}$ was assigned to the inner hydroxyl of Kaol. The other bands corresponded to inner-surface hydroxyl. Generally, the inner hydroxyl groups are not influenced by the intercalation and grafting due to the hydrogen of inner hydroxyls being oriented towards the vacant sites. However, the inner-surface hydroxyls are readily affected by the interlayer modifications. When DMSO was intercalated, the band at $3690 \mathrm{~cm}^{-1}$ shifted to $3695 \mathrm{~cm}^{-1}$, while the band at 3665 shifted to $3660 \mathrm{~cm}^{-1}$ (Figure 2). The new bands at 3536 and $3505 \mathrm{~cm}^{-1}$ were due to the formation of moderately strong hydrogen bonding between some of the inner surface hydroxyls and the sulphonyl oxygen [57]. Besides, the characteristic stretching vibrations of $\mathrm{C}-\mathrm{H}$ at $3023 \mathrm{~cm}^{-1}$ (asymmetry) and $2937 \mathrm{~cm}^{-1}$ (symmetry) corresponded to $-\mathrm{CH}_{2}$ of DMSO. The Si-O bond stretching bands of Kaol at 1115,1029 and $1007 \mathrm{~cm}^{-1}$ were observed at 1123, 1025 and $1109 \mathrm{~cm}^{-1}$ for Kaol-DMSO. Additionally, the Al-OH bending vibrations of Kaol at $912 \mathrm{~cm}^{-1}$ shifted to $904 \mathrm{~cm}^{-1}$.

Then, after the Kaol-DMSO was washed 10 times with fresh $\mathrm{MeOH}$, the $\mathrm{C}-\mathrm{H}$ stretching bands of DMSO vanished completely, due to the removal of excess DMSO. By the intercalation of DMSO, the bands at $3695 \mathrm{~cm}^{-1}$ appeared. After treatment with fresh $\mathrm{MeOH}$, this band was weakened. Compared with Kaol-DMSO, The Si-O stretching band of Kaol-MeOH at $1040 \mathrm{~cm}^{-1}$ appeared again. All the changes of bands were attributed to the deintercalation of Kaol-DMSO and intercalation of Kaol with $\mathrm{MeOH}$. As seen in the FTIR spectrum of Kaol-SDS, the bands of inner-surface hydroxyl groups have no obvious changes. The band at $3693 \mathrm{~cm}^{-1}$ was attributed to the tiny shift of the hydroxyl stretching band to $3692 \mathrm{~cm}^{-1}$ (Figure 2). Additionally, a new inconspicuous band at $3542 \mathrm{~cm}^{-1}$ may be due to SDS hydrogen bonded to hydroxyl surface groups. In comparison with Kaol-MeOH, the characteristic bands of Kaol-SDS were shown at 2915, 2850, 1652, 1556 and $1472 \mathrm{~cm}^{-1}$. The first two bands originated from the $-\mathrm{CH}_{2}$ of SDS corresponding to the asymmetry and symmetry stretching bands, respectively. The absorption band at $1472 \mathrm{~cm}^{-1}$ was ascribed to the $\mathrm{C}-\mathrm{O}$ stretching band. On the other hand, the variation of the $\mathrm{Si}-\mathrm{O}$ stretching band was not obvious. Therefore, the FTIR spectra variations 
of Kaol-SDS further confirmed the successful intercalation of SDS into kaolinite, which was in good agreement with the XRD analyses.

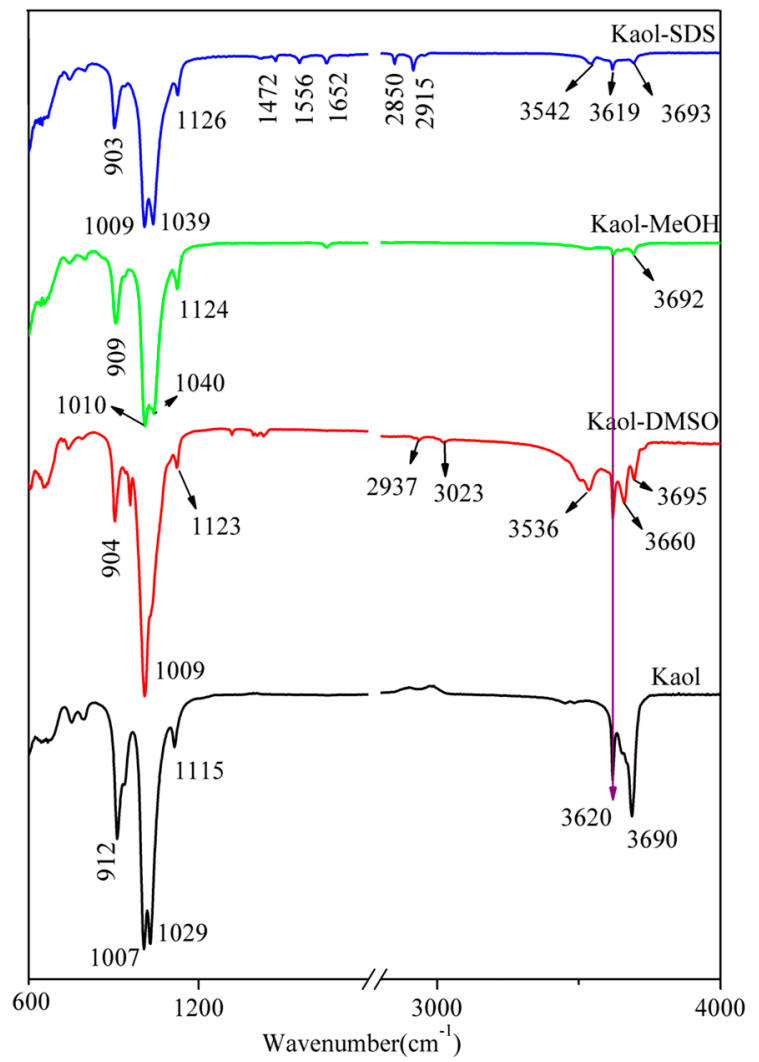

Figure 2. FTIR spectra of Kaol, Kaol-DMSO, Kaol-MeOH and Kaol-SDS.

\subsection{Thermal Analysis}

The TG/DTG curves of Kaol and its intercalation compounds are shown in Figure 3. In order to investigate the dehydroxylation of Kaol with different treatments, the DTG effect was characterized by extrapolating the temperature of the beginning of the peak (Ti), ending of the peak (Te) and width of the peak $(\mathrm{W}=\mathrm{Te}-\mathrm{Ti})$. The temperatures of $\mathrm{Ti}$ (onset) and $\mathrm{Te}$ (outset) were determined from the intersection of the extrapolated initial baseline and tangent to the frontal and terminal inflection points, respectively. The DTG peaks parameters of the dehydroxylation of Kaol and Kaol intercalation compounds are presented in Table 2. The thermal decomposition of Kaol occurred only in one step observed in the TG curve. This step started at $450{ }^{\circ} \mathrm{C}$ and terminated at $600{ }^{\circ} \mathrm{C}$ and was related to the dehydroxylation of Kaol. The DTG peak of Kaol centered at $520^{\circ} \mathrm{C}$ was clearly observed, where a mass loss of $12.6 \%$ was attained.

As seen in the TG curve of Kaol-DMSO, there were two steps, for which the first (5.9\% mass loss) took place between 120 and $220^{\circ} \mathrm{C}$ was contributed to the volatilization of DMSO. The second step (3.8\% mass loss) that occurred between $455^{\circ} \mathrm{C}$ and $630^{\circ} \mathrm{C}$ was assigned to the dehydroxylation of Kaol. The DTG maximum of the two processes appeared at 200 and $524^{\circ} \mathrm{C}$, respectively. In comparison with Kaol, while the intercalated Kaol with DMSO did not modify the temperature of the DTG maximum of the dehydroxylation, and the width of the peak decreased (Figure 3, Table 2). From the TG curve of Kaol-MeOH, a strong endothermic peak starting at $400{ }^{\circ} \mathrm{C}$ and ending at $600{ }^{\circ} \mathrm{C}$ was observed, with a mass loss of $2.2 \%$. A less obvious endothermic peak appearing between 60 and $200{ }^{\circ} \mathrm{C}$ was also displayed, which contributed to a mass loss of $12.5 \%$, attributed to the degradation of water, $\mathrm{MeOH}$ and methoxy groups in Kaol layers. The reason that the first peak in the DTG curve of Kaol-MeOH became seriously broadened was the stronger interaction between $\mathrm{MeOH}$ and the hydroxyl of Kaol. 
In comparison with Kaol and Kaol-DMSO, the DTG peak of Kaol-MeOH shifted to a lower temperature (Table 2), which was due to the hydroxyl activation.

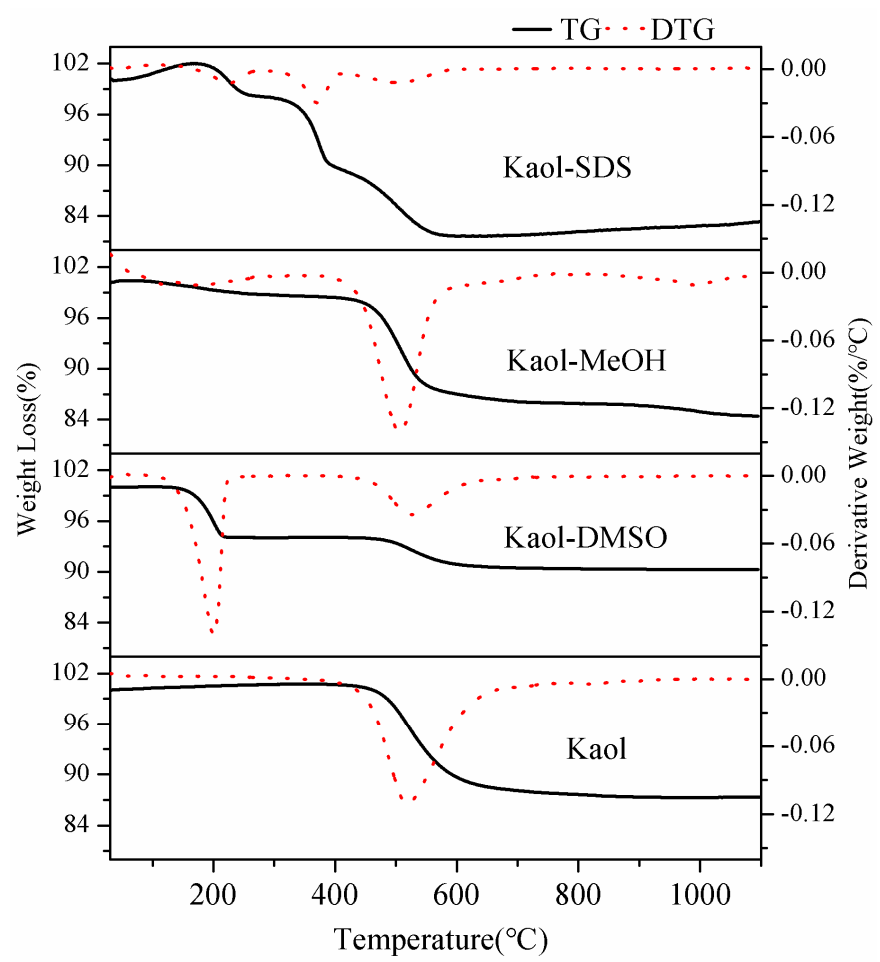

Figure 3. TG /DTG curves of Kaol, Kaol-DMSO, Kaol-MeOH and Kaol-SDS.

Table 2. The corresponding parameters of the dehydroxylation of Kaol and its intercalation compounds.

\begin{tabular}{ccccc}
\hline Samples & DTG Peak $\left({ }^{\circ} \mathbf{C}\right)$ & Ti $\left({ }^{\circ} \mathbf{C}\right)$ & Te $\left({ }^{\circ} \mathbf{C}\right)$ & W $\left({ }^{\circ} \mathbf{C}\right)$ \\
\hline Kaol & 520 & 450 & 632 & 182 \\
Kaol-DMSO & 524 & 456 & 627 & 171 \\
Kaol-MeOH & 507 & 440 & 564 & 124 \\
Kaol-SDS & 502 & 406 & 587 & 181 \\
\hline
\end{tabular}

Four mass losses were observed in the DTG curve of Kaol-SDS, while three main processes were detected in the TG curve. Typically, the first decomposition process occurred below $80{ }^{\circ} \mathrm{C}$, which was ascribed to the removal of externally-absorbed water. Then, the second loss, corresponding to the degradation of external SDS, was observed in the range of $135-275{ }^{\circ} \mathrm{C}$. The third volatilization, which represented the removal of sodium dodecyl sulfate located in the Kaol interlamellar space, occurred between 305 and $410{ }^{\circ} \mathrm{C}$. Lastly, the loss starting at 420 and ending at $600{ }^{\circ} \mathrm{C}$ was attributed to the dehydroxylation of Kaol. It was noteworthy that the dehydroxylation of Kaol-SDS appeared at $502{ }^{\circ} \mathrm{C}$, which was the lowest of all samples, indicating that the activity of hydroxyl groups of Kaol was increased by the intercalation with SDS. This was probably due to the effect of intercalated SDS.

\subsection{Particle Size and Morphology Analysis}

Figure 4 demonstrates the morphologies of Kaol and Kaol products with different treatments. The raw Kaol was mainly composed of typical stacks of hexagonal, large sheet-like and fine-grained particles (Figure 4a). Compared with the original Kaol, no significant changes were observed in the morphology of Kaol-MeOH due to the small interlayer space of Kaol. After the intercalation of SDS, however, the $d$ spacing of Kaol reached up to $4.21 \mathrm{~nm}$, and the Kaol layers were simultaneously 
exfoliated (Figure 4e); because it was obviously found that low aggregated silicate layers were shown and some platy particles scrolled from the edges of Kaol (Figure 4e).
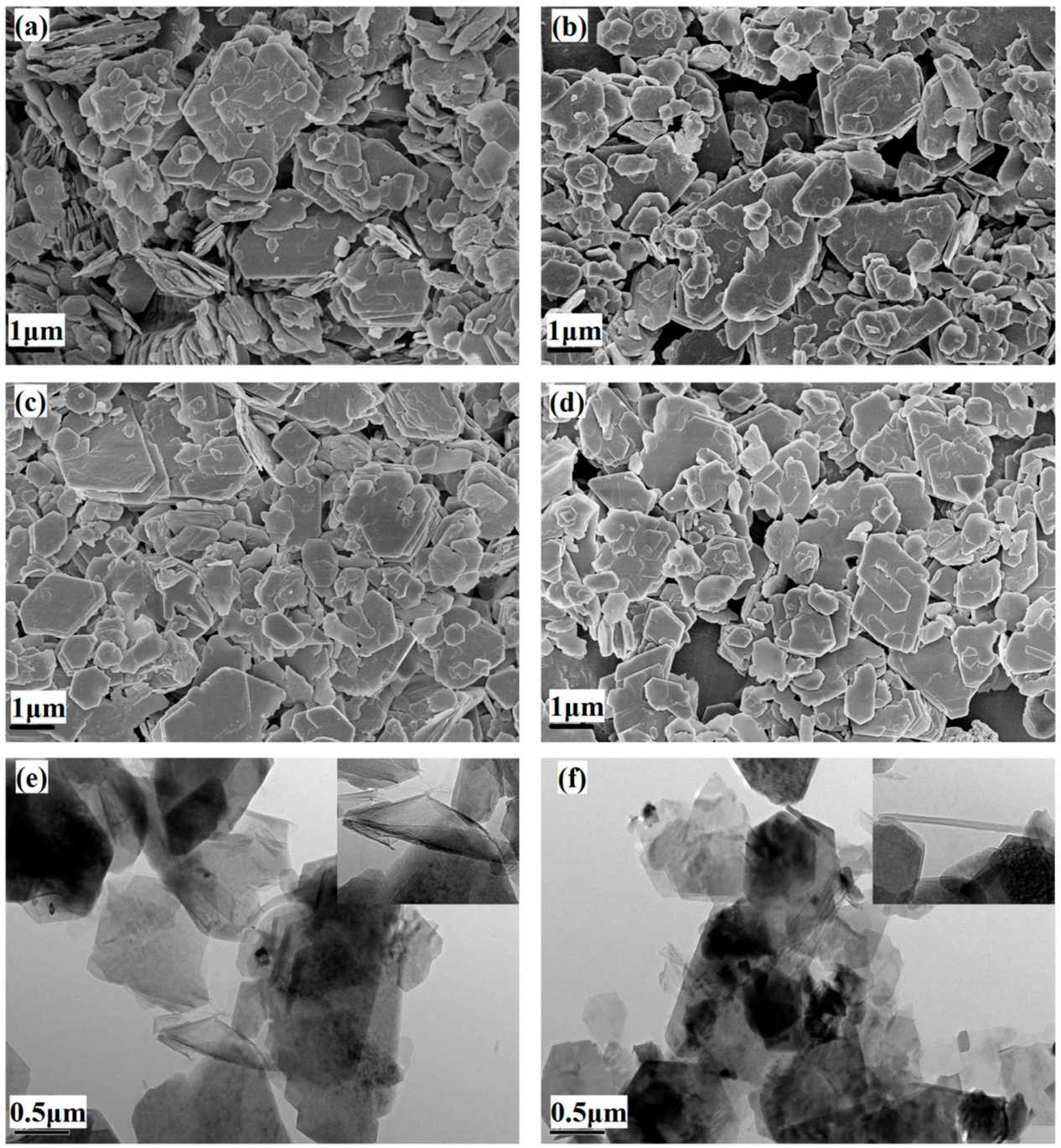

Figure 4. SEM images of (a) Kaol, (b) Kaol-MeOH, (c) Kaol-SDS and (d) Kaol-SDS-U; TEM images of (e) Kaol-SDS and (f) Kaol-SDS-U.

Figure $4 \mathrm{~d}$ displays the morphology of exfoliated Kaol-SDS, which was treated by sonication. In comparison with Kaol-SDS, the SEM images of Kaol-SDS-U also showed nearly no changes. However, the curl degree of the Kaol layer was more serious than that of the Kaol layer without ultrasonication (Figure 4f). Furthermore, completely curled layers are shown in the highly magnified TEM image, indicating that a few Kaol layers would transform into nanoscrolls during the exfoliation process. Previous studies [19,52,58-60] suggested that abundant kaolinite layers would be transformed into nanoscrolls after the intercalation with long chain cationic intercalators such as cetyltrimethylammonium bromide (CTAB), octadearyl dimethyl ammonium chloride (OTAC) and dodecylamine. In comparison with Kaol-SDS and Kaol-SDS-U, however, only a limited number of Kaol layers transformed into nanoscrolls. Most Kaol layers were composed of euhedral particles with a pseudohexagonal morphology.

In order to analyze the particle size variations directly, all samples were characterized by a Malvin particle size test instrument. The grain-size frequency curves of Kaol, Kao-MeOH, Kaol-SDS and Kaol-SDS-U are shown in Figure 5 and Table 3. When raw Kaol was intercalated by DMSO and MeOH 
in turn, the distribution peaks shifted to a small size (Figure 5a,b), and the mean particle diameter of Kaol-MeOH decreased nearly two times (Table 3). In the case of Kaol-SDS, both the size distribution and parameters were similar to Kaol-MeOH, indicating that most Kaol layers were not exfoliated due to the intercalation with SDS. After sonication, however, the particle size of Kaol-SDS was further reduced (Table 3 ). At the same time, there are two obvious distribution peaks (Figure $5 \mathrm{~d}$ ), suggesting two main particle size ranges in the samples.

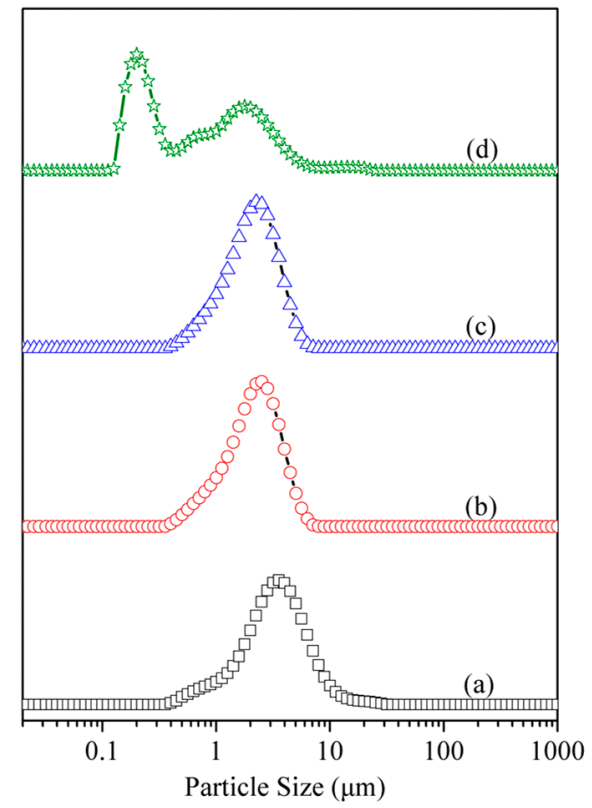

Figure 5. Particle size distribution curves of (a) Kaol, (b) Kaol-MeOH, (c) Kaol-SDS and (d) Kaol-SDS-U.

Table 3. The particle size of raw Kaol and Kaol with different exfoliation methods.

\begin{tabular}{ccccc}
\hline Samples & $\mathbf{D}_{\mathbf{1 0}}(\boldsymbol{\mu m})^{\mathbf{a}}$ & $\mathbf{D}_{\mathbf{5 0}}(\boldsymbol{\mu m})^{\mathbf{a}}$ & $\mathbf{D}_{\mathbf{9 0}}(\boldsymbol{\mu m})^{\mathbf{a}}$ & $\mathbf{D}_{\text {average }}(\boldsymbol{\mu m})$ \\
\hline Kaol & 1.225 & 3.142 & 6.614 & 3.729 \\
Kaol-MeOH & 0.885 & 2.054 & 3.702 & 2.205 \\
Kaol-SDS & 0.885 & 1.955 & 3.507 & 2.104 \\
Kaol-SDS-U & 0.165 & 0.635 & 2.811 & 1.274
\end{tabular}

${ }^{\text {a }} \mathrm{D}_{10}, \mathrm{D}_{50}$ and $\mathrm{D}_{90}$ indicate the diameters at $10 \%, 50 \%$ and $90 \%$ of the cumulative volume distribution, respectively.

The results of the morphology and particle size of Kaol with different treatments indicated that although the intercalation of Kaol with SDS expanded the interlayer space, very few Kaol layers were exfoliated. The Kaol-SDS under sonication seriously reduced the average grain size of Kaol, while the platelets were broken into small ones. Moreover, it was easily noted that the particle size of the exfoliated Kaol layers via sonication was closer to the nanoscale.

\section{Conclusions}

Kaol-SDS has been successfully prepared by using Kaol-MeOH as an intermediate. The XRD analyses indicated that the basal spacing of Kaol expanded to $4.21 \mathrm{~nm}$ after intercalation with SDS. From the thermal analyses, it was found that the dehydroxylation temperature of Kaol-SDS evenly reduced, maybe due to the hydroxyl activation of Kaol. The morphology analysis confirmed that few layers of Kaol-MeOH were exfoliated, and few partially-curled Kaol sheets occurred in the intercalation procedures. The sonication of Kaol-SDS further exfoliated Kaol layers into very thin sheets that curled up to form nanoscrolls. However, most of the Kaol layers remained intact. Based on the particle size analysis, the average grain size of Kaol-SDS-U decreased greatly in comparison with Kaol-SDS, and 
some Kaol layers were close to the nanoscale. Thus, it could be hopeful to provide a new exfoliation method to obtain large aspect ratios of Kaol layers.

Acknowledgments: This work was supported by the National Nature Science Foundation of China (51034006), the National Key R\&D Program of China (2017YFB0310903), the Key R\&D Program of Hunan Province (2017GK2251) and the Central South University Graduate Independent Exploration Innovation Program (2017zzts191).

Author Contributions: Qinfu Liu and Shilong Zhang conceived of the project. Xiaochao Zuo wrote the initial drafts of the work. Qinfu Liu and Huaming Yang wrote the final paper. Xiaochao Zuo designed and performed the experiments and characterized the samples. Xiaochao Zuo and Ding Wang analyzed the data. All authors discussed the results and commented on the manuscript.

Conflicts of Interest: The authors declare no conflict of interest.

\section{References}

1. Kotal, M.; Bhowmick, A.K. Polymer nanocomposites from modified clays: Recent advances and challenges. Prog. Polym. Sci. 2015, 51, 127-187. [CrossRef]

2. Cui, Y.B.; Kumar, S.; Kona, B.R.; van Houcke, D. Gas barrier properties of polymer/clay nanocomposites. RSC Adv. 2015, 5, 63669-63690. [CrossRef]

3. Zhang, Y.D.; Liu, Q.F.; Xiang, J.J.; Zhang, S.L.; Frost, R.L. Influence of the structural characteristic of pyrolysis products on thermal stability of styrene-butadiene rubber composites reinforced by different particle sized kaolinites. J. Therm. Anal. Calorim. 2014, 117, 1201-1210. [CrossRef]

4. Bromberg, L.; Straut, C.M.; Centrone, A.; Wilusz, E.; Hatton, T.A. Montmorillonite functionalized with pralidoxime as a material for chemical protection against organophosphorous compounds. ACS Appl. Mater. Interface 2011, 3, 1479-1484. [CrossRef] [PubMed]

5. Zhang, Y.D.; Liu, Q.F.; Zhang, Q.; Lu, Y.P. Gas barrier properties of natural rubber/kaolin composites prepared by melt blending. Appl. Clay Sci. 2010, 50, 255-259. [CrossRef]

6. Yahaya, L.E.; Adebowale, K.O.; Menon, A.R.R. Mechanical properties of organomodified kaolin/natural rubber vulcanizates. Appl. Clay Sci. 2009, 46, 283-288. [CrossRef]

7. Mirzadeh, A.; Kokabi, M. The effect of composition and draw-down ratio on morphology and oxygen permeability of polypropylene nanocomposite blown films. Eur. Polym. J. 2007, 43, 3757-3765. [CrossRef]

8. Cabeda, L.; Gimenez, E.; Lagaron, J.M.; Gavara, R.; Saura, J.J. Development of EVOH-kaolinite nanocomposites. Polymer 2004, 45, 5233-5238. [CrossRef]

9. Bundy, W.; Ishley, J. Kaolin in paper filling and coating. Appl. Clay Sci. 1991, 5, 397-420. [CrossRef]

10. Xia, X.N.; Zeng, X.L.; Liu, J.; Xu, W.J. Preparation and characterization of epoxy/kaolinite nanocomposites. J. Appl. Polym. Sci. 2010, 118, 2461-2466. [CrossRef]

11. Cheng, H.F.; Zhang, Z.L.; Liu, Q.F.; Leung, J. A new method for determining platy particle aspect ratio: A kaolinite case study. Appl. Clay Sci. 2014, 97-98, 125-131. [CrossRef]

12. Lu, C.S.; Mai, Y.W. Influence of aspect ratio on barrier properties of polymer-clay nanocomposites. Phys. Rev. Lett. 2005, 95, 1-4. [CrossRef] [PubMed]

13. Zhang, S.L.; Liu, Q.F.; Yang, Y.J.; Wang, D.; He, J.K.; Sun, L.Y. Preparation; morphology; and structure of kaolinites with various aspect ratios. Appl. Clay Sci. 2017, 147, 117-122. [CrossRef]

14. Zoromba, M.S.; Belal, A.A.M.; Ali, A.E.M.; Helaly, F.M.; Abd El-Hakim, A.A.; Badran, A.S. Preparation and characterization of some NR and SBR formulations containing different modified kaolinite. Polym. Plast. Technol. Eng. 2007, 46, 529-535. [CrossRef]

15. Zhang, Y.D.; Zhang, Q.; Liu, Q.F.; Cheng, H.F.; Frost, R.L. Thermal stability of styrene butadiene rubber (SBR) composites filled with kaolinite/silica hybrid filler. J. Therm. Anal. Calorim. 2014, 115, 1013-1020. [CrossRef]

16. Zhang, Y.M.; Liu, Q.F.; Zhang, S.L.; Zhang, Y.D.; Zhang, Y.F.; Liang, P. Characterization of kaolinite/styrene butadiene rubber composite: Mechanical properties and thermal stability. Appl. Clay Sci. 2016, 124-125, 167-174. [CrossRef]

17. Zhang, Q.; Liu, Q.F.; Zhang, Y.D.; Cheng, H.F.; Lu, Y.P. Silane-grafted silica-covered kaolinite as filler of styrene butadiene rubber. Appl. Clay Sci. 2012, 65-66, 134-138. [CrossRef]

18. Cheng, H.F.; Liu, Q.F.; Zhang, J.S.; Yang, J.; Frost, R.L. Delamination of kaolinite-potassium acetate intercalates by ball-milling. J. Colloid Interface Sci. 2010, 348, 355-359. [CrossRef] [PubMed] 
19. Kuroda, Y.; Ito, K.; Itabshi, K.; Kuroda, K. One-Step Exfoliation of kaolinites and their transformation into nanoscrolls. Langmuir 2011, 27, 2028-2035. [CrossRef] [PubMed]

20. Nicolosi, V.; Chhowalla, M.; Kanatzidis, M.G.; Strano, M.S.; Coleman, J.N. Liquid exfoliation of layered materials. Science 2013, 340, 1226419. [CrossRef]

21. Pi, Z.B.; Liu, Z.Q.; Yang, C.; Tian, X.K.; Fei, J.B.; Zheng, J.H. Exfoliation of kaolinite by urea-intercalation precursor and microwave irradiation assistance process. Front. Earth Sci. China 2007, 1, 26-29. [CrossRef]

22. Li, X.G.; Liu, Q.F.; Cheng, H.F.; Zhang, S.; Frost, R.L. Mechanism of kaolinite sheets curling via the intercalation and delamination process. J. Colloid Interface Sci. 2015, 444, 74-80. [CrossRef] [PubMed]

23. Zuo, X.C.; Wang, D.; Zhang, S.L.; Liu, Q.F.; Yang, H.M. Effect of intercalation agents on morphology of exfoliated kaolinite. Minerals 2017, 7, 249. [CrossRef]

24. Makó, É.; Kristóf, J.; Horváth, E.; Vágvölgyi, V. Kaolinite-urea complexes obtained by mechanochemical and aqueous suspension techniques-A comparative study. J. Colloid Interface Sci. 2009, 330, 367-373. [CrossRef] [PubMed]

25. Cheng, H.F.; Liu, Q.F.; Liu, J.; Sun, B.; Kang, Y.X.; Frost, R.L. TG-MS-FTIR (evolved gas analysis) of kaolinite-urea intercalation complex. J. Therm. Anal. Calorim. 2014, 116, 195-203. [CrossRef]

26. Long, M.; Zhang, Y.; Shu, Z.; Tang, A.D.; Ouyang, J.; Yang, H.M. $\mathrm{Fe}_{2} \mathrm{O}_{3}$ nanoparticles anchored on 2D kaolinite with enhanced antibacterial activity. Chem. Commun. 2017, 5346, 6255-6258. [CrossRef] [PubMed]

27. Long, M.; Zhang, Y.; Huang, P.; Chang, S.; Hu, Y.H.; Yang, Q.; Mao, L.F.; Yang, H.M. Emerging nanoclay composite for effective hemostasis. Adv. Funct. Mater. 2017. [CrossRef]

28. Zhang, Y.; Long, M.; Huang, P.; Chang, S.; Hu, Y.H.; Yang, H.M.; Tang, A.D.; Mao, L.F. Intercalated 2D nanoclay for emerging drug delivery in cancer therapy. Nano Res. 2017, 10, 2633-2643. [CrossRef]

29. Frost, R.L.; Kristof, J.; Paroz, G.N.; Kloprogge, J.T. Modification of the kaolinite hydroxyl surfaces through intercalation with potassium acetate under pressure. J. Colloid Interface Sci. 1998, 208, 478-486. [CrossRef] [PubMed]

30. Liu, S.Y.; Yang, H.M. Composite of coal-series kaolinite and capric-lauric acid as form-stable phase-change material. Energy Technol. 2015, 3, 77-83. [CrossRef]

31. Zhang, S.; Liu, Q.F.; Cheng, H.F.; Zeng, F.G. Combined experimental and theoretical investigation of interactions between kaolinite inner surface and intercalated dimethyl sulfoxide. Appl. Surf. Sci. 2015, 331, 234-240. [CrossRef]

32. Fu, L.J.; Yang, H.M. Structure and electronic properties of transition metal doped kaolinite nanoclay. Nanoscale Res. Lett. 2017, 12, 1-7. [CrossRef] [PubMed]

33. Yan, Z.L.; Fu, L.J.; Hu, Y.H.; Yang, H.M. Functionalized 2D Clay derivative: Hybrid nanosheets with unique lead sorption behaviors and interface structure. Adv. Mater. Interface 2017. [CrossRef]

34. Yan, Z.L.; Fu, L.J.; Zuo, X.C.; Yang, H.M. Green assembly of stable and uniform silver nanoparticles on 2D silica nanosheets for catalytic reduction of 4-nitrophenol. Appl. Catal. B Environ. 2018, 226, 23-30. [CrossRef]

35. Yan, Z.L.; Fu, L.J.; Zuo, X.C.; Yang, H.M.; Ouyang, J. Amino-functionalized Hierarchical Porous $\mathrm{SiO}_{2}-\mathrm{AlOOH}$ Composite Nanosheets with Enhanced Adsorption Performance. J. Hazard. Mater. 2018, 344, 1090-1100. [CrossRef]

36. Fu, L.J.; Yang, H.M.; Hu, Y.H.; Wu, D.; Navrotsky, A. Tailoring mesoporous $\gamma-\mathrm{Al}_{2} \mathrm{O}_{3}$ properties by transition metal doping: A combined experimental and computational study. Chem. Mater. 2017, 29, 1338-1349. [CrossRef]

37. Yan, Z.L.; Yang, H.M.; Ouyang, J.; Tang, A.D. In situ loading of highly-dispersed CuO nanoparticles on hydroxyl-group-rich $\mathrm{SiO}_{2}-\mathrm{AlOOH}$ composite nanosheets for $\mathrm{CO}$ catalytic oxidation. Chem. Eng. J. 2017, 316, 1035-1046. [CrossRef]

38. Peng, K.; Fu, L.J.; Li, X.Y.; Ouyang, J.; Yang, H.M. Stearic acid modified montmorillonite as emerging microcapsules for thermal energy storage. Appl. Clay Sci. 2017, 138, 100-106. [CrossRef]

39. Liu, S.Y.; Yan, Z.L.; Fu, L.J.; Yang, H.M. Hierarchical nano-activated silica nanosheets for thermal energy storage. Sol. Energy Mater. Sol. Cells 2017, 167, 140-149. [CrossRef]

40. Shu, Z.; Zhang, Y.; Yang, Q.; Yang, H.M. Halloysite nanotubes supported Ag and ZnO nanoparticles with synergistically enhanced antibacterial activity. Nanoscale Res. Lett. 2017, 12, 1-7. [CrossRef] [PubMed]

41. Hou, K.; Wen, X.; Yan, P.; Tang, A.D.; Yang, H.M. Tin oxide-carbon coated sepiolite nanofibers with enhanced lithium-ion storage property. Nanoscale Res. Lett. 2017, 12, 1-10. [CrossRef] [PubMed] 
42. Jin, J.; Ouyang, J.; Yang, H.M. Pd nanoparticles and MOFs synergistically hybridized halloysite nanotubes for hydrogen storage. Nanoscale Res. Lett. 2017, 12,1-9. [CrossRef] [PubMed]

43. Hou, K.; Ouyang, J.; Zheng, C.H.; Zhang, J.H.; Yang, H.M. Chemically modified sepiolite fibers for reinforcing resin brake composites. Mater. Express 2017, 7, 104-112. [CrossRef]

44. Shen, Q.; Ouyang, J.; Zhang, Y.; Yang, H.M. Lauric acid/modified sepiolite composite as a form-stable phase change material for thermal energy storage. Appl. Clay Sci. 2017, 146, 14-22. [CrossRef]

45. Peng, K.; Yang, H.M. Carbon hybridized montmorillonite nanosheets: Preparation, structural evolution and enhanced adsorption performance. Chem. Commun. 2017, 53, 6085-6088. [CrossRef] [PubMed]

46. Fu, L.J.; Yang, H.M.; Tang, A.D.; Hu, Y.H. Engineering a tubular mesoporous silica nanocontainer with well-preserved clay shell from natural halloysite. Nano Res. 2017, 10, 2782-2799. [CrossRef]

47. Komori, Y.; Sugahara, Y. A kaolinite-NMF-methanol intercalation compound as a versatile intermediate for further intercalation reaction of kaolinite. J. Mater. Res. 1998, 13, 930-934. [CrossRef]

48. Komori, Y.; Sugahara, Y.; Kuroda, K. Intercalation of alkylamines and water into kaolinite with methanol kaolinite as an intermediate. Appl. Clay Sci. 1999, 15, 241-252. [CrossRef]

49. Matusik, J.; Kłapyta, Z. Characterization of kaolinite intercalation compounds withbenzylalkylammonium chlorides using XRD; TGADTA and CHNS elemental analysis. Appl. Clay Sci. 2013, 83-84, 433-440. [CrossRef]

50. Matusik, J.; Kłapyta, Z.; Olejniczak, Z. NMR and IR study of kaolinite intercalation compounds with benzylalkylammonium chlorides. Appl. Clay Sci. 2013, 83-84, 426-432. [CrossRef]

51. Gardolinski, J.E.F.C.; Lagaly, G. Grafted organic derivatives of kaolinite: I. Synthesis; chemical and rheological characterization. Clay Miner. 2005, 40, 537-546. [CrossRef]

52. Gardolinski, J.E.F.C.; Lagaly, G. Grafted organic derivatives of kaolinite: II. Intercalation of primary n-alkylamines and delamination. Clay Miner. 2005, 40, 547-556. [CrossRef]

53. Liu, Q.F.; Li, X.; Cheng, H.F. Insight into the self-adaptive deformation of kaolinite layers into nanoscrolls. Appl. Clay Sci. 2016, 124-125, 175-182. [CrossRef]

54. Sidheswaran, P.; Bhat, A.N.; Ganguli, P. Intercalation of salts of fatty acids into kaolinite. Clays Clay Miner. 1990, 38, 29-32. [CrossRef]

55. Wang, S.; Zuo, X.; Cheng, H.F.; Yang, Y.; Liu, Q.F. Structural model and de-intercalation kinetics of kaolinite-methanol-sodium stearate intercalation compound. J. Braz. Chem. Soc. 2016, 27, 1311-1318. [CrossRef]

56. Li, X.G.; Cui, X.J.; Wang, S.; Wang, D.; Li, K.; Liu, Q.F.; Komarneni, S. Methoxy-grafted kaolinite preparation by intercalation of methanol: Mechanism of its structural variability. Appl. Clay Sci. 2017, 137, 241-248. [CrossRef]

57. Horváth, E.; Kristóf, J.; Frost, R.L. Vibrational spectroscopy of intercalated kaolinites. Part I. Appl. Spectrosc. Rev. 2010, 45, 130-147. [CrossRef]

58. Dong, W.J.; Li, W.J.; Yu, K.F.; Krishna, K.; Song, L.Z.; Wang, X.F.; Wang, Z.C.; Marc-Oliver, C.; Feng, S.H. Synthesis of silica nanotubes from kaolin clay. Chem. Commun. 2003, 11, 1302-1303. [CrossRef]

59. Liu, Q.F.; Wang, D.; Guo, P.; Zhang, S.L.; Cheng, H.F.; Li, X.G.; Zhang, S. Preparation and structural characterization of kaolinite intercalation compound with Series of quaternary anmmonium salt. J. Chin. Ceram. Soc. 2015, 2, 222-230.

60. Yuan, P.; Tan, D.Y.; Annabi-Bergaya, F.; Yan, W.C.; Liu, D.; Liu, Z.W. From platy kaolinite to aluminosilicate nanoroll via one-step delamination of kaolinite: Effect of the temperature of intercalation. Appl. Clay Sci. 2013, 83-84, 68-76. [CrossRef]

(C) 2018 by the authors. Licensee MDPI, Basel, Switzerland. This article is an open access article distributed under the terms and conditions of the Creative Commons Attribution (CC BY) license (http:/ / creativecommons.org/licenses/by/4.0/). 